\title{
Computational Study of Coordinated Ni(II) Complex with High Nitrogen Content Ligands
}

\author{
Bo Tang, Jia-Hai Ye, and Xue-Hai Ju \\ School of Chemical Engineering, Nanjing University of Science and Technology, Nanjing 210094, China \\ Correspondence should be addressed to Xue-Hai Ju, xhju@mail.njust.edu.cn
}

Received 29 January 2011; Accepted 21 March 2011

Academic Editors: A. Barbero, G. Giambastiani, and C. Thomas

Copyright ( 2011 Bo Tang et al. This is an open access article distributed under the Creative Commons Attribution License, which permits unrestricted use, distribution, and reproduction in any medium, provided the original work is properly cited.

Density functional computations were performed on two tetracoordinated Ni(II) complexes as high nitrogen content energetic materials (1: dinickel bishydrazine ter[(1H-Tetrazol-3-yl)methan-3yl]-1H-tetrazole and 2: dinickel tetraazide ter[(1H-Tetrazol-3yl)methan-3yl]-1H-tetrazolate). The geometrical structures, relative stabilities and sensitivities, and thermodynamic properties of the complexes were investigated. The energy gaps of frontier molecular orbital (HOMO and LUMO) and vibrational spectroscopies were also examined. There are minor Jahn-Teller distortions in both complexes 1 and 2, with two long Ni-N bond lengths and two short ones. The enthalpies of combustion for both complexes are over $3600 \mathrm{~kJ} / \mathrm{mol}$. The $\mathrm{N}-\mathrm{N}$ bond lengths in the moieties of hydrazine and azide ligands increase in the coordination process compared to those of the isolated molecules.

\section{Introduction}

The development of weapon ammunition and energetic materials requires higher integrate performance including powerful efficacy, controllable energy release, insensitivity, and being friendly to environment. However, conventional energetic materials cannot fulfill all of these requests simultaneously. High energy density materials (HEDM) offer the needful properties mentioned above fortunately, with additional advantages of safety and low characteristic signal [1-6]. A key property for the design and synthesis of new energetic materials is the heat of formation (HOF) [7], which is used to assess potential performance in technology applications. Since measuring HOF as well as other essential information through experimental sample is inaccessible and dangerous for HEDM, thus we resort to theoretical methods. Therefore, discovery and exploitation of new types of HEDM through theoretical evaluations are our focus in this paper.

In the latest decades, investigators started to consider transition metal as the component of energetic materials because transition metal possesses numerous excellences [8-12]. Herein, we chose transition metal nickel as the object and emphasized nitrogen-coordinated $\mathrm{Ni}(\mathrm{II})$ complex. Among multitudinous complexes containing transition metal, polynuclear transition metal complexes are rather noticeable, interesting both from a fundamental and from an application viewpoint. In previous literatures, $\mathrm{N}_{3}{ }^{-}$, phenoxo and di-2-pyridyl ketone have been used to bridge the center metal ion $\mathrm{Ni}(\mathrm{II})$ [11-15]. For example, all the $\mathrm{Ni}$ atoms in $\left[\mathrm{Ni}_{6}\left(\mathrm{CO}_{3}\right)\left(\mathrm{N}_{3}\right)_{6}\{\text { pyCOpyC }(\mathrm{O})(\mathrm{OMe}) \text { py }\}_{3}\right.$ $\left.(\mathrm{MeOH})_{3}\right]\left(\mathrm{ClO}_{4}\right)_{2}$ are hexacoordinate [14], exhibiting distorted octahedral coordination geometries. While in some other complexes, the $\mathrm{Ni}$ (II) exists as the form of tetracoordinate, by which $\mathrm{Ni}$ (II) coordinates with either four nitrogen atoms on a plane or with three nitrogen atoms and one sulfur exhibiting pseudotetrahedron [16, 17].

A variety of derivatives-involve tetrazole have recently been synthesized in experiment $[18,19]$ and verified a good selectivity for coordination with $\mathrm{Ni}(\mathrm{II})$. Consequently tetrazole with four potential coordinated nitrogen atoms which are ready to bridge transition metals of our required binuclear transition metal complexes, become the candidate group. In order to expand the magnitude of nitrogen content and diversification of bridging situation, we used tetrazole derivatives to accomplish the bridging of two $\mathrm{Ni}(\mathrm{II})$ into complexes. With four tetrazoles substituting the hydrogens on the methane in a manner that the $\mathrm{C}$-substituted tetrazoles are more stable than the corresponding $\mathrm{N}$-substituted isomers [7], the ligand $\mathbf{L}$ (Figure 1) was produced. Compared to 


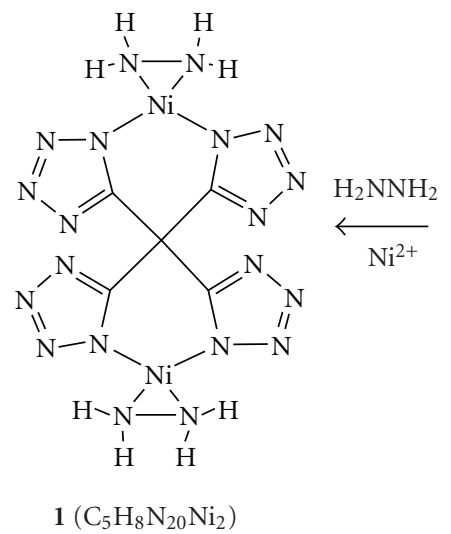

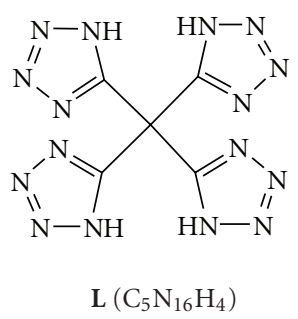

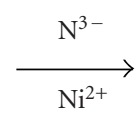<smiles></smiles>

$2\left(\mathrm{C}_{5} \mathrm{H}_{4} \mathrm{~N}_{28} \mathrm{Ni}_{2}\right)$

FIgURE 1: Molecular structures of 1, 2, and L (1): dinickel bishydrazine ter[(1H-Tetrazol-3-yl)methan-3yl]-1H-tetrazole, (2): dinickel tetraazide ter[(1H-Tetrazol-3-yl)methan-3yl]-1H-tetrazolate, and $(\mathbf{L})$ : tetra $(1 H$-Tetrazol-5-yl)methane.

the single tetrazole, each $\mathbf{L}$ has four times of nitrogen atoms to coordinate with $\mathrm{Ni}(\mathrm{II})$.

One thing that has to be paid attention to is that $\mathbf{L}$ can exist in three kinds of forms towards tetrazoles: tetrazoles, tetrazolates, and tetrazolium (namely neutral, deprotonated and protonated tetrazoles). Considering the interaction with positive metal ion of $\mathrm{Ni}(\mathrm{II})$, previous two forms are preferentially employed to coordinate with $\mathrm{Ni}$ (II). In the light of distinguishing form of $\mathbf{L}$, we should have two other groups to coordinate with $\mathrm{Ni}$ (II) separately, that is, a neutral or a negatively charged group. To add more nitrogen content into the complexes, the $\mathrm{N}_{2} \mathrm{H}_{4}$ and $\mathrm{N}_{3}{ }^{-}$were selected as additional ligands. Accordingly, the target compounds are 1 and 2 as shown in Figure 1. We optimized the structures of 1 and 2 with DFT-B3LYP method. The infrared spectroscopy was simulated. The changes of standard thermodynamic properties in the coordinating reactions were predicted, the stability constants were evaluated from the changes of standard Gibbs free energies. The combustion heats were calculated for the title complexes. Finally, the energy gaps were used to evaluate the sensitivity of the complexes. These results are beneficial for experimental investigators to advance thorough researches on these metallic complexes with high nitrogen content.

\section{Computational Methods}

The density functional B3LYP can produce accurately and economically the heats of formation for compounds containing tetrazole or transition metal $[7,20]$. Previous researches also indicated that B3LYP is one of the best choices for metallic complexes $[21,22]$. Many kinds of basis sets were taken into consideration for comparison. The CEP-31G, LanL2DZ, and SDD pseudopotential basis sets are commonly used for metallic atom and $6-31+\mathrm{G}^{* *}$ and $3-21+\mathrm{G}^{*}$ for nonmetallic atoms. The $\mathrm{Ni}\left(\mathrm{N}_{3}\right)_{4}{ }^{2-}$ was used as a benchmark to see if the outcome is consistent with experimental data. At the beginning, we tried all the combinations of the abovementioned basis sets. As a result, only the combination of SDD with $6-31+\mathrm{G}^{* *}$ or $3-21+\mathrm{G}^{*}$ produced the convergence structures. We obtained the following optimized bond lengths and angles of $\mathrm{Ni}\left(\mathrm{N}_{3}\right)_{4}{ }^{2-}$ when the combination of SDD with $3-21+\mathrm{G}^{*}$ was used: $\theta(\mathrm{N}-\mathrm{N}-\mathrm{N})=166.71^{\circ}, 167.61^{\circ}$, $171.11^{\circ}$ and $177.81^{\circ} . \mathrm{r}(\mathrm{Ni}-\mathrm{N})=2.0341 \AA, 2.0431 \AA, 2.0281 \AA$, and $1.9731 \AA$. Both the bond lengths and angles are in good agreement to the experimental values of the azidecoordinated $\mathrm{Ni}(\mathrm{II})$ complex $\left[\mathrm{Ni}_{2} \mathrm{~L}_{2}\left(\mathrm{~N}_{3}\right)_{2}\left(\mathrm{H}_{2} \mathrm{O}\right)_{2}\right]$, whose $\theta(\mathrm{N}-\mathrm{N}-\mathrm{N})=178.4(5)^{\circ}$, and $\mathrm{r}(\mathrm{Ni}-\mathrm{N})$ are in range of $2.028-$ $2.096 \AA$ [12]. In addition, calculated bond lengths are also in good agreement and the experimental $r(\mathrm{Ni}-\mathrm{N})=1.995 \AA$ and $2.001 \AA$ in the tetracoordinate $\mathrm{Ni}$ (II) complex [17]. The good agreement between our calculated structure of isolated $\mathrm{Ni}\left(\mathrm{N}_{3}\right)_{4}{ }^{2-}$ molecule with the experiment made us confident to proceed to the next step: optimization for title compound with DFT-B3LYP method.

Ligand $\mathbf{L}$, hydrazine, azide anion, and the coordinated $\mathrm{Ni}$ complexes generated from the Chem3D were fully optimized at the DFT-B3LYP level by the Berny method [23] with basis sets of SDD for $\mathrm{Ni}$ atom and $3-21+\mathrm{G}^{*}$ for nonmetallic atoms. The computations were performed with the Gaussian 03 package [24] at the B3LYP level. The optimizations were performed without any symmetry restrictions using the default convergence criteria in the programs. All of the optimized structures were characterized to be true local energy minima on the potential energy surfaces without imaginary frequencies.

\section{Results and Discussion}

3.1. Molecular Structures. Figure 2 shows the optimized structures of $\mathbf{1}$ and 2 , and the corresponding $\mathrm{Ni}-\mathrm{N}$ bond lengths were listed in Table 1 . The nickel(II) ion is tetrahedrally coordinated in both the complexes. The $\mathrm{Ni}(23)$ atom is coplanar with $\mathrm{N}(4), \mathrm{N}(30)$, and $\mathrm{N}(33)$ in 1 , but $\mathrm{N}(15)$ is perpendicular to the plane. On the opposite side, the $\mathrm{Ni}(22)$ atom is coplanar with $\mathrm{N}(10), \mathrm{N}(24)$, and $\mathrm{N}(27)$, with $\mathrm{N}(18)$ perpendicular to it. Similarly, $\mathrm{Ni}(33)$ atom is coplanar with $\mathrm{N}(34), \mathrm{N}(35)$, and $\mathrm{N}(18)$ in 2, with $\mathrm{N}(15)$ perpendicular to the plane. On the opposite side, $\mathrm{Ni}(26)$ atom is coplanar with $\mathrm{N}(8), \mathrm{N}(27)$, and $\mathrm{N}(28)$, with $\mathrm{N}(2)$ perpendicular to it. 


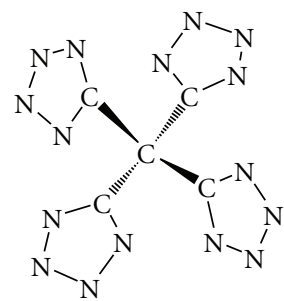

$\mathbf{L}$

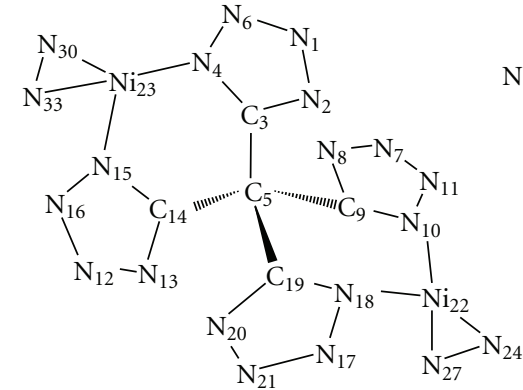

1

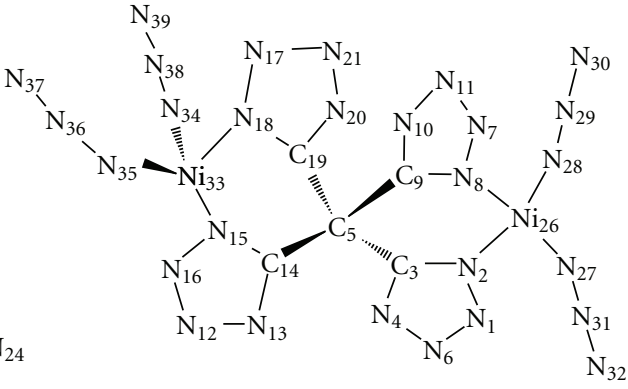

FIGURE 2: Optimized molecular structures of title complexes and ligand (hydrogen atom omitted for clarity).

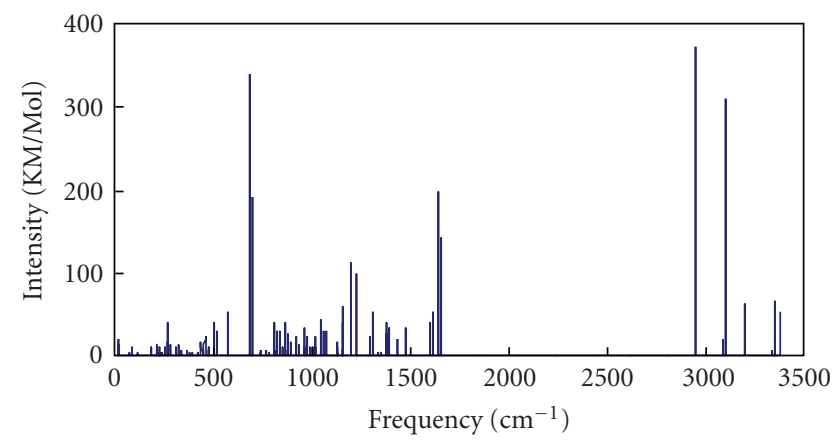

1

(a)

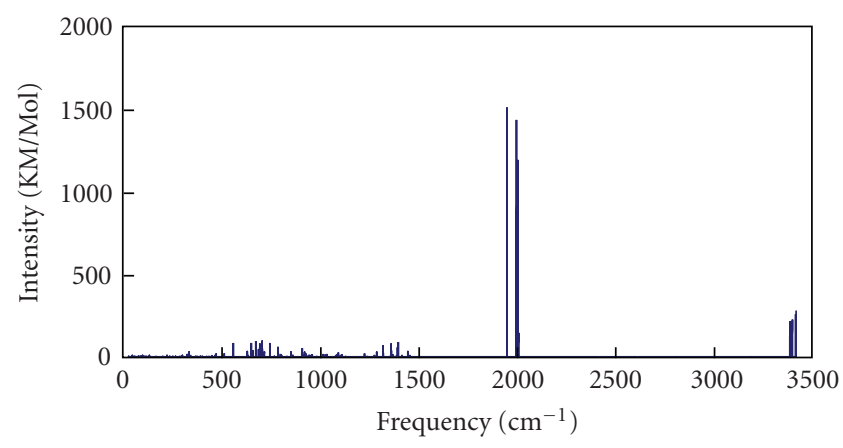

2

(b)

FIGURE 3: Simulated IR spectroscopies of title complexes.

As can be seen from Table 1, there is a difference in the $\mathrm{Ni}-\mathbf{L}$ bond strength in $\mathbf{1}$ and $\mathbf{2}$. The coordinated bonds between $\mathrm{Ni}$ and $\mathrm{N}$ of $\mathrm{N}_{2} \mathrm{H}_{4}$ are over $2 \AA$ in 1 , while those between $\mathrm{Ni}$ and $\mathrm{N}$ of $\mathbf{L}$ are less that $2 \AA$. $\mathrm{Ni}$ atom in $\mathbf{1}$ combines with $\mathbf{L}$ more strongly than with $\mathrm{N}_{2} \mathrm{H}_{4}$, with $\mathbf{L}$ being deprotonated and deformed. On the contrary, the coordinated bonds between $\mathrm{Ni}$ and $\mathrm{N}_{3}{ }^{-}$for 2 are less than $2 \AA$, while those between $\mathrm{Ni}$ and $\mathbf{L}$ are larger than $2 \AA$. Ni atom in 2 combines with $\mathrm{L}$ less strongly than with $\mathrm{N}_{3}{ }^{-}$, and the structure of $\mathbf{L}$ hardly changes as compared to its uncoordinated one. As a whole, there are minor Jahn-Teller distortions in both $\mathbf{1}$ and $\mathbf{2}$, with two long $\mathrm{Ni}-\mathrm{N}$ lengths and two short ones.

Observation of the geometrical structure of $\mathrm{N}_{2} \mathrm{H}_{4}$ and $\mathrm{N}_{3}{ }^{-}$before and after coordination process found that the $\mathrm{r}(\mathrm{N}-\mathrm{N})=1.5571$ and $1.5601 \AA$ in hydrazine moiety, for 1 are obviously larger than $1.4621 \AA$ in the isolated $\mathrm{N}_{2} \mathrm{H}_{4}$ molecule. Also, the hydrogen atoms of hydrazine moiety for 1 prefer an eclipsed configuration in contrast to the stagger one of isolated $\mathrm{N}_{2} \mathrm{H}_{4}$ molecule (hydrazine). As for 2 , the four azides are nearly linear with the $\mathrm{N}-\mathrm{N}-\mathrm{N}$ angles being from $177.71^{\circ}$ to $179.01^{\circ}$, indicating that the N-N-N angle hardly changes in the coordination process. The $\mathrm{N}-\mathrm{N}$ bond lengths for the azide ligand in complex 2 are 1.17 to $1.21 \AA$ (the longer one neighboring with $\mathrm{Ni}$ ), which are larger than 1.15 to $1.17 \AA$ of the isolated azide acid.
TABLE 1: Optimized bond length $(\AA)$ of Ni-N.

\begin{tabular}{lccc}
\hline \multicolumn{2}{c}{ Compound 1} & \multicolumn{2}{c}{ Compound 2 } \\
Bond & Length & Bond & Length \\
\hline $\mathrm{Ni}(22)-\mathrm{N}(24)$ & 2.0395 & $\mathrm{Ni}(26)-\mathrm{N}(27)$ & 1.9155 \\
$\mathrm{Ni}(22)-\mathrm{N}(27)$ & 2.0595 & $\mathrm{Ni}(26)-\mathrm{N}(28)$ & 1.9295 \\
$\mathrm{Ni}(23)-\mathrm{N}(30)$ & 2.0635 & $\mathrm{Ni}(33)-\mathrm{N}(34)$ & 1.9345 \\
$\mathrm{Ni}(23)-\mathrm{N}(33)$ & 2.0655 & $\mathrm{Ni}(33)-\mathrm{N}(35)$ & 1.9585 \\
$\mathrm{Ni}(22)-\mathrm{N}(10)$ & 1.9685 & $\mathrm{Ni}(26)-\mathrm{N}(2)$ & 2.0175 \\
$\mathrm{Ni}(22)-\mathrm{N}(18)$ & 1.9635 & $\mathrm{Ni}(26)-\mathrm{N}(8)$ & 2.0625 \\
$\mathrm{Ni}(23)-\mathrm{N}(4)$ & 1.9935 & $\mathrm{Ni}(33)-\mathrm{N}(15)$ & 2.1085 \\
$\mathrm{Ni}(23)-\mathrm{N}(15)$ & 1.9715 & $\mathrm{Ni}(33)-\mathrm{N}(18)$ & 2.0265 \\
\hline
\end{tabular}

3.2. Infrared Spectroscopy. Figure 3 showed the calculated IR spectroscopy for $\mathbf{1}$ and $\mathbf{2}$. The vibrational frequencies produced by DFT-B3LYP were multiplied by a scale factor 0.89 [25]. For complex $\mathbf{1}$, the $250 \mathrm{~cm}^{-1}$ mode is assigned to the cooperative rocking of the complex. Frequency around $630 \mathrm{~cm}^{-1}$ is associated with the $\mathrm{H}-\mathrm{N}-\mathrm{H}$ rocking modes for the $\mathrm{N}_{2} \mathrm{H}_{4}$ moiety and this mode exhibit very large intensities as a result of large dipole moment change. Frequency at $747 \mathrm{~cm}^{-1}$ is associated with the N-N stretching modes of a tetrazole ring. The $1067-1129 \mathrm{~cm}^{-1}$ modes are associated with the stretches of $\mathrm{H}-\mathrm{N}-\mathrm{H}$ wagging for the $\mathrm{N}_{2} \mathrm{H}_{4}$ moiety. 
TABLE 2: Thermodynamic properties and stability constants for 1 and $\mathbf{2}$ at various temperatures *

\begin{tabular}{ccccccccc}
\hline Compound & $\mathrm{TEMP} / \mathrm{K}$ & $\Delta \mathrm{E} / \mathrm{kJ} / \mathrm{mol}$ & $\Delta \mathrm{ZPE} / \mathrm{kJ} / \mathrm{mol}$ & $\Delta H_{T} / \mathrm{kJ} / \mathrm{mol}$ & $\Delta \mathrm{H} / \mathrm{kJ} / \mathrm{mol}$ & $\Delta \mathrm{S} / \mathrm{kJ} / \mathrm{mol}$ & $\Delta \mathrm{G} / \mathrm{kJ} / \mathrm{mol}$ & $\mathrm{log} \mathrm{K}$ \\
\hline & 298.15 & -689.92 & -67.08 & -17.07 & -774.07 & -0.71 & -561.82 & 98.43 \\
& 600.00 & -689.92 & -67.08 & -21.04 & -778.04 & -0.73 & -338.22 & 29.45 \\
1 & 900.00 & -689.92 & -67.08 & -24.41 & -781.41 & -0.74 & -111.57 & 6.48 \\
& 1200.00 & -689.92 & -67.08 & -28.93 & -785.93 & -0.75 & 118.05 & -5.14 \\
& 1500.00 & -689.92 & -67.08 & -34.94 & -791.94 & -0.76 & 350.24 & -12.20 \\
\hline \multirow{4}{*}{2} & 298.15 & -1039.98 & -15.96 & -21.59 & -1077.53 & -1.07 & -759.34 & 133.04 \\
& 600.00 & -1039.98 & -15.96 & -25.07 & -1081.01 & -1.09 & -428.30 & 37.29 \\
& 900.00 & -1039.98 & -15.96 & -24.21 & -1080.15 & -1.09 & -96.01 & 5.57 \\
& 1200.00 & -1039.98 & -15.96 & -22.51 & -1078.46 & -1.10 & 237.51 & -10.34 \\
& 1500.00 & -1039.98 & -15.96 & -21.31 & -1077.26 & -1.10 & 571.87 & -19.91 \\
\hline
\end{tabular}

${ }^{*} \Delta \mathrm{H}=\Delta \mathrm{E}+\Delta \mathrm{ZPE}+\Delta \mathrm{H}_{T}$.

TABLE 3: Calculated changes of thermodynamic properties in combustion ${ }^{\mathrm{a}}$.

\begin{tabular}{cccccc}
\hline Compound & TEMP/K & $\Delta \mathrm{E} / \mathrm{kJ} / \mathrm{mol}$ & $\Delta \mathrm{ZPE} / \mathrm{kJ} / \mathrm{mol}$ & $\Delta \mathrm{H}_{T} / \mathrm{kJ} / \mathrm{mol}$ & 62.72 \\
\\
\hline
\end{tabular}

${ }^{a}$ Combustion reactions: $\mathrm{C}_{5} \mathrm{H}_{8} \mathrm{~N}_{20} \mathrm{Ni}_{2}+8 \mathrm{O}_{2}=5 \mathrm{CO}_{2}+4 \mathrm{H}_{2} \mathrm{O}+10 \mathrm{~N}_{2}+2 \mathrm{NiO}$ for complex $\mathbf{1}$, and $\mathrm{C}_{5} \mathrm{H}_{4} \mathrm{~N}_{2} 8 \mathrm{Ni}_{2}+7 \mathrm{O}_{2}=5 \mathrm{CO}_{2}+2 \mathrm{H}_{2} \mathrm{O}+14 \mathrm{~N}_{2}+2 \mathrm{NiO}$ for complex 2.

The $1270 \mathrm{~cm}^{-1}$ mode is assigned to the C-C stretching of ligand L. The $2720-2900 \mathrm{~cm}^{-1}$ modes are of the $\mathrm{N}-$ $\mathrm{H}$ stretching of the $\mathrm{N}_{2} \mathrm{H}_{4}$ moiety with two strong peaks. For complex 2, there are only two major peak regions at $1810-1860 \mathrm{~cm}^{-1}$ and $3140-3170 \mathrm{~cm}^{-1}$. The former modes associated with $\mathrm{N}-\mathrm{N}$ stretching of the azide exhibit strong intensities. While the latter modes associated with $\mathrm{N}-\mathrm{H}$ stretching on the tetrazole ring exhibits weak intensity. It should be noted that the intensities of strong peaks of 2 are much larger than those of $\mathbf{1}$, since the $\mathrm{N}-\mathrm{N}$ bond stretching of the azide moiety induces great change of the dipole moment for the former.

3.3. Stability Constants of the Complexes. The changes of the thermodynamic functions for reaction $\mathrm{M}+\mathrm{nL}=\mathrm{ML}_{n}$ were listed in Table 2 . The stability constants of the complexes were then derived from the equation of $\Delta G=-R T \ln K$.

As can be seen from Table 2, the stability constant of 2 is larger than that of $\mathbf{1}$ at low temperature, while at high temperature, $\mathbf{2}$ is more unstable than $\mathbf{1}$. Therefore, $\mathbf{2}$ is readily easy to synthesize compared to $\mathbf{1}$. The stability constants for both the complexes decrease as temperature increases. There are inversion temperatures for the complexes at the range of 900-1200 K. The complexes become unstable above $1043 \mathrm{~K}$ and $985 \mathrm{~K}$ for $\mathbf{1}$ and 2 , respectively. Of course, the stability constants and the inversion temperatures refer to the metalligand bonds.

3.4. Changes of Thermodynamic Properties in Combustion. The changes of thermodynamic properties in combustion were tabulated in Table 3. As can be seen from Table 3, the complex 2 releases more energy in combustion or explosion compared to $\mathbf{1}$. With temperature increasing, the absolute values of $\Delta_{c} H$ increase. Of course, the actual energies being released would be less than the predicted values since the combustion enthalpies were evaluated on condition of rich oxygen.

3.5. Energy Gap. The HOMO-LUOM energy gap could be regarded as the quantitative index in evaluating the impact sensitivity of energetic complexes with similar geometric structure. The less the energy gap is, the more sensitive the energetic complex is. Table 4 listed the energies of HOMO and LUMO and their gaps. The energy gap of the complex 2 with azide ligand is as small as $2.37 \mathrm{eV}$. This is in good agreement with the fact that the metallic azide is widely used as initiator due to its high sensitivity. Judged by the large 
TABLE 4: The frontier orbital energy and their gap.

\begin{tabular}{lccc}
\hline Compound & $\mathrm{HOMO} / \mathrm{eV}$ & $\mathrm{LUMO} / \mathrm{eV}$ & Energy gap/eV \\
\hline $\mathbf{1}$ & -2.48 & -7.53 & 5.05 \\
$\mathbf{2}$ & -3.71 & -6.08 & 2.37 \\
\hline
\end{tabular}

difference of energy gap between $\mathbf{1}$ and $\mathbf{2}$, it can be speculated that $\mathbf{1}$ is an insensitive explosive.

\section{Conclusion}

DFT-B3LYP computations in combination with SDD basis set for $\mathrm{Ni}$ and $3-21+\mathrm{G}^{*}$ for nonmetallic atoms were performed on dinickel bishydrazine ter[( $1 H$-Tetrazol-3-yl)methan-3yl]- $1 H$-tetrazole and dinickel tetraazide ter[ $(1 H$ Tetrazol-3-yl)methan-3yl]-1H-tetrazolate. Tetra( $1 H$-Tetrazol-5-yl)methane was used to bridge two center metal ions $\mathrm{Ni}(\mathrm{II})$. The $\mathrm{Ni}$ (II) can coordinate tetrahedrally with tetratetrazolyl-methane and hydrazine/azide anion. The metalligand bonds are stable below $1000 \mathrm{~K}$, judged from the stability constants. Both complexes release a great amount of heats in combustion. Complex 1, coordinated with ligands of tetra( $1 H$-Tetrazol-5-yl)methane and hydrazine, was predicted to have low sensitivity.

\section{References}

[1] M. R. Manaa, E. J. Reed, L. E. Fried, and N. Goldman, "Nitrogen-rich heterocycles as reactivity retardants in shocked insensitive explosives," Journal of the American Chemical Society, vol. 131, no. 15, pp. 5483-5487, 2009.

[2] J. C. Gálvez-Ruiz, G. Holl, K. Karaghiosoff et al., "Derivatives of 1,5-diamino-1H-tetrazole: a new family of energetic heterocyclic-based salts," Inorganic Chemistry, vol. 44, no. 12, pp. 4237-4253, 2005.

[3] D. L. Strout, "Cage isomers of N14 and N16: nitrogen molecules that are not a multiple of six," Journal of Physical Chemistry A, vol. 108, no. 49, pp. 10911-10916, 2004.

[4] L. Y. Bruney, T. M. Bledson, and D. L. Strout, "What makes an N12 cage stable?" Inorganic Chemistry, vol. 42, no. 24, pp. 8117-8120, 2003.

[5] A. Hammerl and T. M. Klapötke, "Tetrazolylpentazoles: nitrogen-rich compounds," Inorganic Chemistry, vol. 41, no. 4, pp. 906-912, 2002.

[6] K. Karaghiosoff, T. M. Klapötke, P. Mayer, C. M. Sabaté, A. Penger, and J. M. Welch, "Salts of methylated 5aminotetrazoles with energetic anions," Inorganic Chemistry, vol. 47, no. 3, pp. 1007-1019, 2008.

[7] Z. X. Chen, J. M. Xiao, H. M. Xiao, and Y. N. Chiu, "Studies on heats of formation for tetrazole derivatives with density functional theory B3LYP method," Journal of Physical Chemistry A, vol. 103, no. 40, pp. 8062-8066, 1999.

[8] C. Sita, V. K. Mohan, and M. G. R. Reddy, "Studies on thermal decomposition and explosive properties of some novel metal complexes of aryl mercapto tetrazoles," Journal of Energetic Materials, vol. 11, pp. 1-37, 1993.

[9] M. H. V. Huynh, M. A. Hiskey, and R. Gilardi, "Preparation and explosive properties of tetraamminebis(3,5-dinitro-1,2,4triazolato-N1 )copper(II)," Journal of Energetic Materials, vol. 23, no. 1, pp. 27-32, 2005.
[10] M. Comet, V. Pichot, B. Siegert, F. Schnell, F. Ciszek, and D. Spitzer, "Phosphorus-based nanothermites: a new generation of energetic materials," Journal of Physics and Chemistry of Solids, vol. 71, no. 2, pp. 64-68, 2010.

[11] J. Bian, Y. Chang, and J. Zhang, "Theoretical studies on the magnetic bistability of dinickel complex tuned by azide," Journal of Physical Chemistry A, vol. 112, no. 14, pp. 31863191, 2008.

[12] P. Mukherjee, M. G. B. Drew, C. J. Gómez-García, and A. Ghosh, "The crucial role of polyatomic anions in molecular architecture: structural and magnetic versatility of five nickel(II) complexes derived from A N,N,O-donor schiff base ligand," Inorganic Chemistry, vol. 48, no. 13, pp. 5848-5860, 2009.

[13] P. Paul and K. Nag, "Sulfur-nitrogen-bonded metal chelates. 18. 1,3-dipolar cycloadditions to coordinated azide in nickel(II) complexes of the types $\left[\mathrm{Ni}(\mathrm{S}-\mathrm{N}-\mathrm{N})\left(\mathrm{N}_{3}\right)\right]$ and $[\mathrm{S}-\mathrm{N}-$ $\left.\mathrm{N}) \mathrm{Ni}\left(\mathrm{N}_{3}\right) \mathrm{Ni}(\mathrm{N}-\mathrm{N}-\mathrm{S})\right]\left(\mathrm{ClO}_{4}\right)$ ]," Inorganic Chemistry, vol. 26, no. 18, pp. 2969-2974, 1987.

[14] A. N. Georgopoulou, C. P. Raptopoulou, V. Psycharis, R. Ballesteros, B. Abarca, and A. K. Boudalis, "Ferromagnetic $\mathrm{Cu}_{4}^{\mathrm{II}}, \mathrm{Co}_{4}^{\mathrm{II}}$, and $\mathrm{Ni}_{6}^{\mathrm{II}}$ azido complexes derived from metalassisted methanolysis of di-2,6-(2-pyridylcarbonyl)pyridine," Inorganic Chemistry, vol. 48, pp. 3167-3176, 2009.

[15] S. Mandai, V. Balamurugan, F. Lloret, and R. Mukherjee, "Syntheses, X-ray structures, and physicochemical properties of phenoxo-bridged dinuclear nickel(II) complexes: kinetics of transesterification of 2-hydroxypropyl-p-nitrophenylphosphate," Inorganic Chemistry, vol. 48, no. 16, pp. 75447556, 2009.

[16] J. Liu, J. Xiao, S. B. Choi et al., "The electronic structures of Co and Ni tetraazaannulenes," Journal of Physical Chemistry B, vol. 110, no. 51, pp. 26180-26184, 2006.

[17] S. Chattopadhyay, T. Deb, J. L. Petersen, V. G. Young, and M. P. Jensen, "Steric titration of arylthiolate coordination modes at pseudotetrahedral nickel(II) centers," Inorganic Chemistry, vol. 49, no. 2, pp. 457-467, 2010.

[18] T. M. Klapötke and C. M. Sabaté, "Nitrogen-rich tetrazolium azotetrazolate salts: a new family of insensitive energetic materials," Chemistry of Materials, vol. 20, no. 5, pp. 17501763, 2008.

[19] T. M. Klapötke, J. Stierstorfer, and A. U. Wallek, "Nitrogenrich salts of 1-methyl-5-nitriminotetrazolate: an auspicious class of thermally stable energetic materials," Chemistry of Materials, vol. 20, no. 13, pp. 4519-4530, 2008.

[20] N. J. Mayhall, K. Raghavachari, P. C. Redfern, and L. A. Curtiss, "Investigation of gaussian4 theory for transition metal thermochemistry," Journal of Physical Chemistry A, vol. 113, no. 17, pp. 5170-5175, 2009.

[21] P. E. M. Siegbahn, "Quantum chemical studies of redox-active enzymes," Faraday Discussions, vol. 124, pp. 289-296, 2003.

[22] D. V. Chachkov and O. V. Mikhailov, "DFT B3LYP calculation of the spatial structure of $\mathrm{Co}(\mathrm{II}), \mathrm{Ni}(\mathrm{II})$, and $\mathrm{Cu}(\mathrm{II})$ template complexes formed in ternary systems metal(II) iondithiooxamide-formaldehyde," Russian Journal of Inorganic Chemistry, vol. 54, no. 12, pp. 1952-1956, 2009.

[23] H. B. Schlegel, "Optimization of equilibrium geometries and transition structures," Journal of Physical Chemistry, vol. 3, pp. 214-218, 1982.

[24] M. J. Frisch, G. W. Trucks, H. B. Schlegel et al., Gaussian 03, Revision B.03, Gaussian, Inc., Pittsburgh, Pa, USA, 2003.

[25] M. W. Wong, "Vibrational frequency prediction using density functional theory," Chemical Physics Letters, vol. 256, no. 4-5, pp. 391-399, 1996. 


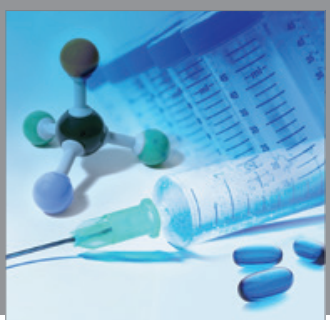

International Journal of

Medicinal Chemistry

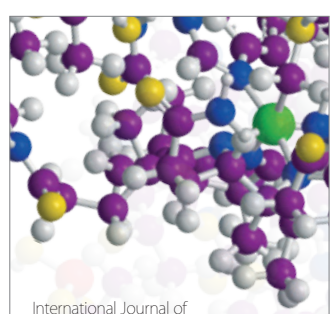

Carbohydrate Chemistry

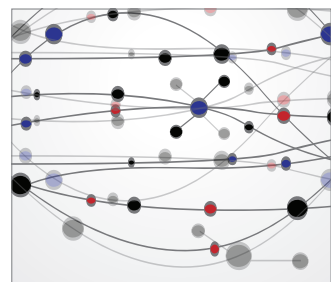

The Scientific World Journal
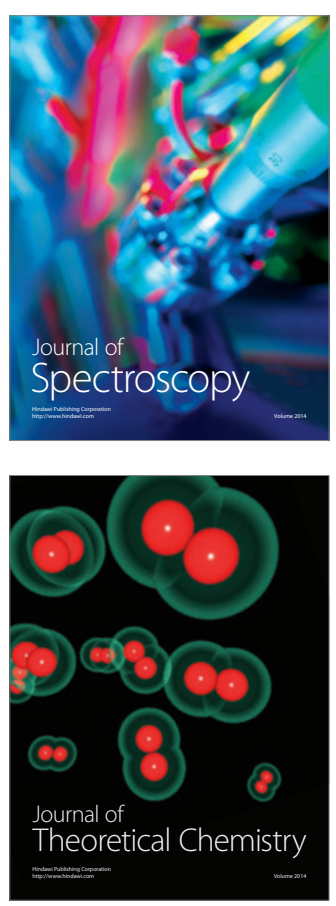
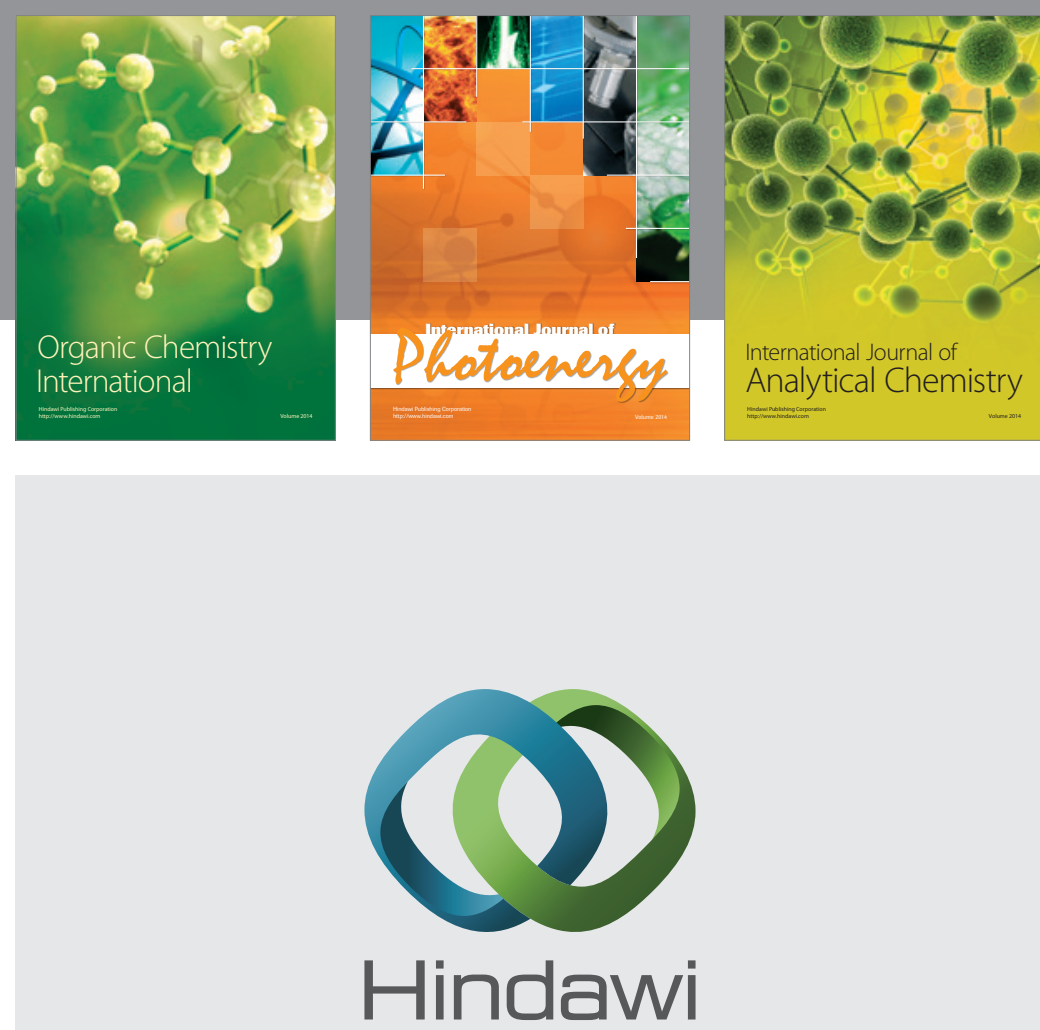

Submit your manuscripts at

http://www.hindawi.com
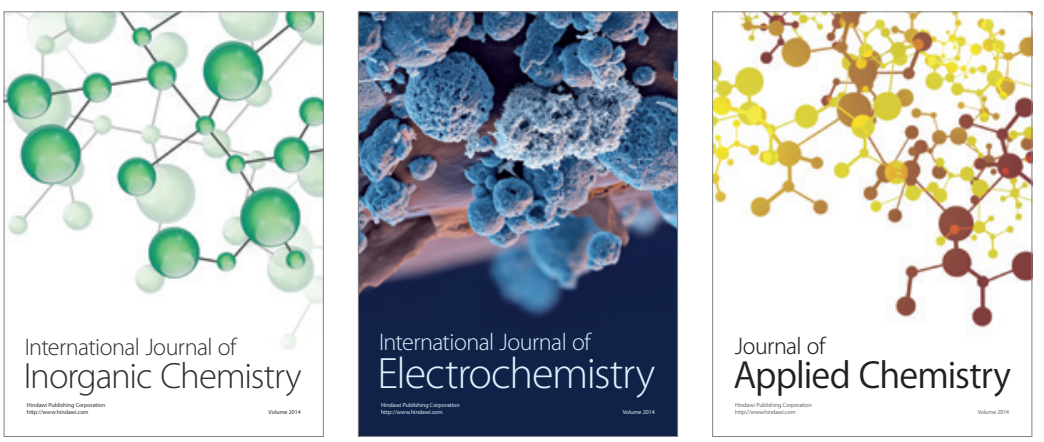

Journal of

Applied Chemistry
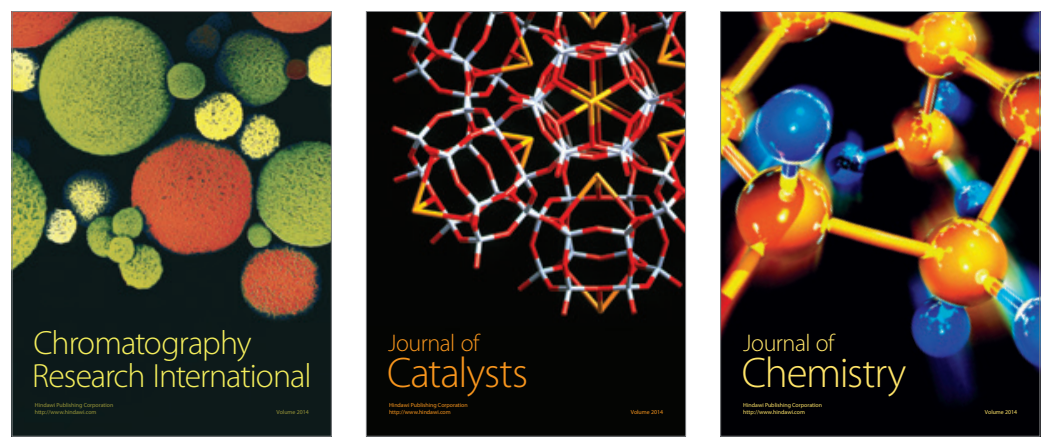
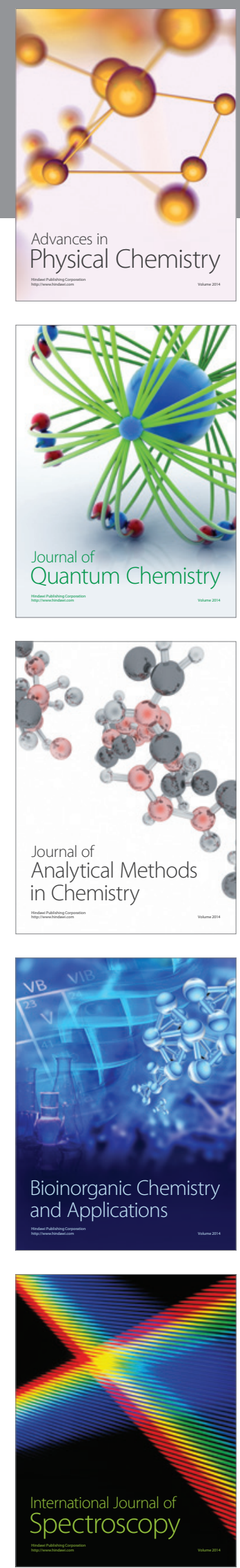